\title{
Choosing quality indicators for quality prediction of egg in circulation
}

\author{
Hye-Ok Lee, Ji-Young Kim, Byeong-Sam Kim* \\ Korea Food Research Institute, Seongnam 463-746, Korea
}

\section{계란의 유통 중 품질예측을 위한 품질지표 선정}

\author{
이혜옥·김지영 · 김병삼* \\ 한국식품연구원
}

\begin{abstract}
This study was conducted to identify quality indicators of the freshness of chicken eggs circulating in domestic markets. We first stored freshly-laid eggs at temperatures of $0,10,20$, and $30^{\circ} \mathrm{C}$, investigated their weight-loss rate, specific gravity, color, york index, albumen index, Haugh unit (HU), pH, and sensory evaluation, and finally analyzed the correlation between each quality characteristic and the sensory preference. At all the storage temperatures, the quality characteristics of the weight-loss rate, specific gravity, yolk index, albumen index, and HU showed significant correlations $(p<0.05)$ with the preference. In particular, the temperature-dependent correlation between the quality characteristics and the sensory preference was significantly higher with increasing storage temperatures and weight-loss rates $(r=-0.78 ; r=-0.93 ; r=-0.95 ;$ and $r=-0.99)$, albumen index $(r=0.66 ; r=0.89 ; r=$ 0.89 ; and $r=0.93$ ), and $\mathrm{HU}$ values $(r=0.64 ; r=0.92 ; r=0.96 ;$ and $r=0.98)$ at $0,10,20$, and $30^{\circ} \mathrm{C}$, respectively $(p<0.01)$. The Color and $\mathrm{pH}$ examinations yielded disparate results, and further research is needed to determine the methods of using the characteristics as quality indicators. We believe that the changes in the weight-loss rate, specific gravity, yolk index, albumen index, and $\mathrm{HU}$ are adequate quality indicators of the freshness of egg in circulation.
\end{abstract}

Key words : egg, temperature, sensory evaluation, correlation, quality indicator

\section{서 론}

계란은 단백질, 지방, 비타민, 무기질 등을 골고루 함유하 고 있는 자연계에 존재하는 완전에 가까운 식품으로 비교적 저렴한 비용으로 인체가 필요로 하는 모든 영양소를 제공해 줄 수 있는 경제적인 식량자원이다(1). 또한 계란은 일반 가정의 조리 재료뿐만 아니라 기포성, 기포 안정성, 유화성, 보수성, 응고성, 보호 교질성 등의 물리적 성질을 제공하므 로 각종 식품가공에 다양하게 이용되고 있다(2).

세계 계란 생산량은 1980년대부터 꾸준히 증가하여 현재 62,840 천톤 수준이며 나라별 생산량으로는 중국, 미국, 인 도, 멕시코 순이며 우리나라는 세계 22위 생산국이다(3). 농림수산식품 주요 통계(MIFAFF, 2011)에 보고된 자료에 의하면 우리나라 채란 양계산업의 총생산액은 2011년 기준

*Corresponding author. E-mail : bskim@kfri.re.kr

Phone : 82-31-780-9142, Fax : 82-31-780-9144
13,409 억 원으로 2005 년 대비 $23.5 \%$ 증가하였으며, 그에 따른 소비량도 꾸준하게 증가하고 있는 추세이다(4). 그러 나 계란은 수분함량이 높아 저장과 유통과정에서 계란의 호흡 및 수분증발 등으로 내부의 품질 저하가 발생 할 수 있다는 단점을 가지고 있어 안정성에 많은 논란의 여지를 남기고 있다(5). 실제로 계란의 유통경로는 매우 복잡하며 양계장에서 생산된 계란의 출하기간이 대규모 농가를 제외 한 대부분의 농가에서 실온에서 방치되고 있다. 또한 도매 상이나 소매상으로 거쳐 소비자에게 판매되는 과정에서도 많은 시간이 소요되며, 특히 외부기온이 높은 하절기에는 신선도 유지에 큰 문제점이 될 수 있다(6). 이처럼 국내의 계란 유통구조의 긴 유통기간과 제대로 표시되지 않은 유통 기한, 복잡한 유통구조, 그리고 상온에서의 유통 등이 계란 의 품질을 일정하게 유지하기가 어려운 실정이다 $(7,8)$. 최근 식품의 안정성 확보를 위해 식품의 원재료부터 가 공 및 유통단계, 소비자가 구입하여 섭취할 때까지의 모든 
단계에서 식품내외에 존재하는 위해요소를 정확히 규명하 고 그 노출로부터 초래될 위해성 발생확률을 과학적인 데이 터에 기본을 둔 접근 방법의 중요성이 강조되고 있다 $(9,10)$. 그러므로 계란을 일정 수준의 품질이 유지되는 기간이 어느 정도 될 것인가를 사전에 예측하여 소비자에게 제공하는 것은 매우 중요한 과제이며, 이를 위해서는 식품의 신선도 를 가장 잘 대표할 수 있는 지표를 선정하는 작업이 필요하 다.

따라서 본 연구에서는 계란의 유통 중 신선도를 판정하 기 위하여 산란 직후 $0,10,20$ 및 $30^{\circ} \mathrm{C}$ 에서 저장하면서 중량감모율, 비중, 색도, 난황계수, 난백계수, Haugh unit(HU), $\mathrm{pH}$ 및 관능특성 변화를 조사한 후 각 품질특성과 관능적 기호도와의 상관관계를 분석하여 적정 품질지표를 규명하고자 수행되었다.

\section{재료 및 방법}

\section{재료 및 저장}

본 실험에 사용된 계란은 $1+$ 등급 특란인 무정란으로 2013년 4월 8일 경기도 이천에서 산란된 것을 구입하여 사용하였다. 계란은 Fig. 1과 같이 10 개 단위 $(600 \sim 700 \mathrm{~g})$ 로 포장(pulp mold, 40mm, Green Environtech Co., Ltd., Gyeonggi, Korea)된 것을 0, 10,20 및 $30^{\circ} \mathrm{C}$ 저장고에 저장하 면서 품질분석 및 관능검사를 실시하였다.

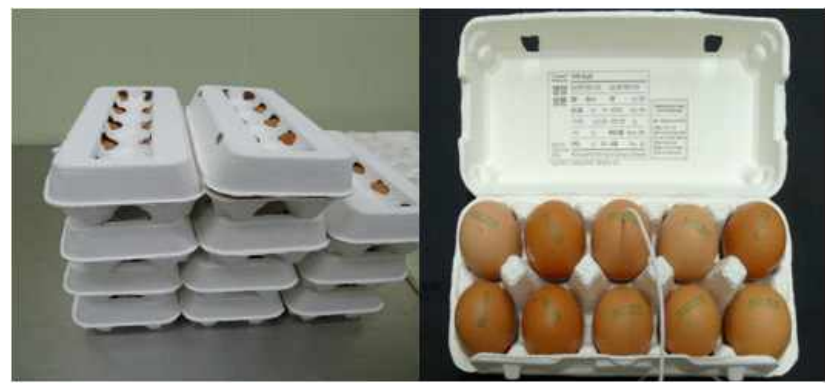

Fig. 1. Appearance of packed egg.

\section{중량감모율}

초기중량과 일정기간 경과 후 측정된 중량의 차이를 초 기중량에 대한 백분율(\%)로 나타내었다.

비 중

비중은 축산물의 가공기준 및 성분규격의 원료란의 시험 법 중 비중에 의한 검사법을 준용하였다. $8 \%, 10 \%$ 및 $11 \%$ 식염수 $2 \mathrm{~L}$ 를 제조하여 비커에 담고, 측정하고자 하는 검체 를 식염수에 띄어 부유되는 정도를 통해 측정하였다. $8 \%$ 의 식염수에 떠오르는 경우 비중 $1.058,8 \%$ 의 식염수에 가라앉 고 $10 \%$ 의 식염수에 떠오르는 경우 비중 $1.060,10 \%$ 의 식염
수에 가라앉고 $11 \%$ 의 식염수에 떠오르는 경우 비중 1.073 그리고 $11 \%$ 의 식염수에 가라앉은 경우 비중 1.080 로 측정 치를 산출하였다.

색 도

계란의 난황과 난백의 색도는 색도계(CR-400, Minolta Co., Osaka, Japan)를 이용하여 L값(명도, lightness), a값(적 색도, redness), b값(황색도, yellowness)으로 표시하였고, 이 때 표준백판의 $\mathrm{L}$ 값은 $97.75, \mathrm{a}$ 값은 $0.49, \mathrm{~b}$ 값은 1.96 인 것을 사용하였다.

난황계수

난황의 높이는 digimatic indicator(ID-C1050XB, Mitutoyo Co., Kawasaki, Japan)를 이용하여 측정하였고, 난황의 직경 은 digimatic caliper(CD-15CPX, Mitutoyo Co.)를 이용하여 가로 및 세로로 측정하고 평균값을 나타내었다. 각 측정값 은 다음 식에 의하여 난황계수를 산출하였다.

난황계수=난황높이 $(\mathrm{mm}) /$ 난황직경 $(\mathrm{mm})$

난백계수

농후난백의 높이는 digimatic indicator를 이용하여 측정 하였고, 농후난백의 직경은 digimatic caliper를 이용하여 장축과 단축을 90 도 방향으로 측정하고 두 값의 평균을 나타내었다. 각 측정값은 다음 식에 의하여 난백계수를 산 출하였다.

난백계수=농후난백의 높이 $(\mathrm{mm}) /$ 농후난백의 직경 $(\mathrm{mm})$

Haugh unit

Haugh unit은 계란의 무게를 측정 한 후, 수평으로 놓여진 평판 위에 할란하여 농후난백의 높이를 측정하였다. 다음 공식에 대입하여 Haugh unit 값을 산출하였다.

Haugh unit $=100 \times \log \left(\right.$ 농후난백의 높이 $+7.57-1.7 \times$ 난중 $\left.{ }^{0.37}\right)$

$\mathrm{pH}$

난황과 난백을 분리한 후 난백과 난황을 비커에 채취하 여 $\mathrm{pH}$ meter(TA-70, DKK-TOA Co., Japan)를 이용하여 측 정하였다.

관능검사

계란의 관능검사는 관능요원 15 명을 대상으로 9점 척도 법을 이용하여 평가하였다. 평가항목은 계란의 색(color), 퍼짐성(spreadability), 이취(off-flavor), 신선도(freshness) 그 리고 전반적인 기호도(overall acceptability)로서 매우 좋다. 9점, 좋다: 7점, 보통이다: 5점, 나쁘다: 3점, 매우 나쁘다. 
1점으로 하였다. 시료는 계란을 깨끗한 유리판에 할란하여 제공하였으며, 난수표를 이용하여 추출된 숫자를 기입하였 다.

\section{통계처리}

자료의 통계처리는 statistical analysis system(SAS) program(SAS Inc., Cary, NC, USA)에 의해 ANOVA 검정과 Duncan's multiple range test 방법을 이용하여 평균값 간에 유의수준 $\mathrm{p}<0.05$ 에서 유의성을 검정하였다. 중량감모율, 비중, 색도, 난황계수, 난백계수, Haugh unit 및 $\mathrm{pH}$ 와 종합적 관능평가지수와의 상관관계는 Pearson's correlation을 사용 하였다.

\section{결과 및 고찰}

\section{품질특성변화}

저장온도에 따른 계란의 저장 중 중량감모율의 변화는 모든 시료에서 저장기간이 경과될수록 감모율이 증가하는 경향을 보였으며 온도가 $0,10,20$ 및 $30^{\circ} \mathrm{C}$ 로 높아짐에 따라 감모율의 변화가 크게 나타났다(Fig. 2). $0^{\circ} \mathrm{C}$ 와 $10^{\circ} \mathrm{C}$ 에서 저장한 경우에는 저장종료일인 105 일까지 $3 \%$ 이하로 나타 났으나, $20^{\circ} \mathrm{C}$ 와 $30^{\circ} \mathrm{C}$ 에서는 저장종료일인 27 일과 11 일에 $5 \%$ 이상의 높은 값을 보였다. 이와 같은 결과는 저장과정 중에 계란 자체적으로 발생되는 호흡에 의한 수분 유출 때문인 것으로 판단된다. Lee 등(11)은 온도가 높을수록 감모율이 증가하였다고 보고하여 본 연구의 결과와 일치하 였다.

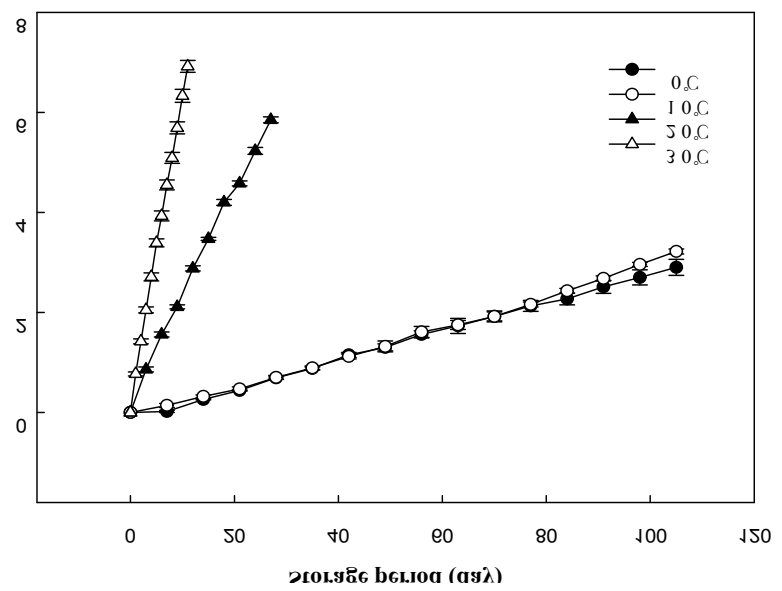

Fig. 2. Changes in the weight-loss rate of egg during storage at 0 , 10,20 , and $30^{\circ} \mathrm{C}$.

Values are presented as means $\pm S D(n=3)$.

저장온도에 따른 계란의 비중 변화를 나타낸 결과는 Fig. 3 과 같다. $20^{\circ} \mathrm{C}$ 와 $30^{\circ} \mathrm{C}$ 에서 저장한 경우에는 비중이 급격하 게 감소하였으나, $0^{\circ} \mathrm{C}$ 와 $10^{\circ} \mathrm{C}$ 에서는 완만하게 감소하는 경
향을 보여 고온저장에 비하여 감소폭이 적게 나타났다. 계 란의 기실은 산란 후 어미 닭의 체온과 외기온도의 차이에 의해 외부의 공기가 내부로 유입되면서 생기는 공기주머니 이다. 저장, 유통 중에 계란의 기실은 껍질의 미세한 공극을 통해 내부의 수분은 감소하고 감소한 수분만큼 외부의 공기 가 유입되어 점점 크게 변화하게 된다(12). 이처럼 저장, 유통 중 발생하는 비중의 감소원인은 중량감모율과 수분의 증발에 의해 기실이 크게 변화하기 때문인 것으로 사료된다.

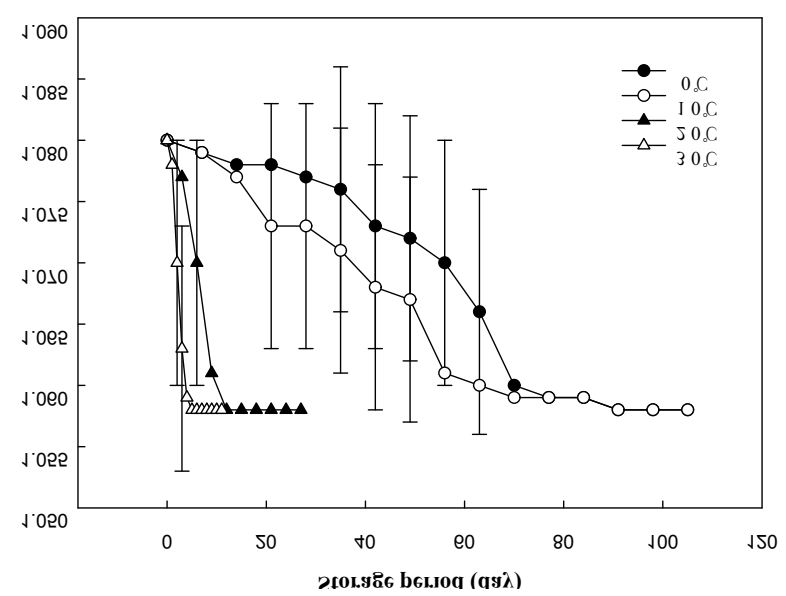

Fig. 3. Changes in the specific gravity of egg during storage at 0 , 10,20 , and $30^{\circ} \mathrm{C}$.

Values are presented as means \pm SD $(n=10)$.

계란의 품질을 결정하는 요인 중 색은 맛, 향 및 영양성분 과 함께 그 식품의 가치를 나타내는 중요한 요소이다. 저장 온도에 따른 계란의 저장 중 난황과 난백의 색도를 분석한 결과 저장기간 동안 증가와 감소를 반복하는 경향을 나타내 어 전반적으로 일정한 경향을 보이지 않았다(Fig. 4). 계란 의 색은 할란 이후에만 평가할 수 있고 또한 난황의 색은 소비자의 기호도, 양계사료의 종류 및 성분배합비 등에 따 라 영향을 받기 때문에 일정한 품질지표로 사용하기는 어려 운 점이 있을 것으로 생각된다.

저장온도에 따른 계란의 내부적 품질지표 중에 하나인 난황계수를 측정하여 나타낸 결과는 Fig. 5 와 같다. $0^{\circ} \mathrm{C}$ 와 $10^{\circ} \mathrm{C}$ 는 저장종료일인 105 일까지 난황계수가 0.42 와 0.31 로 나타났으며 $20^{\circ} \mathrm{C}$ 와 $30^{\circ} \mathrm{C}$ 는 각각의 저장종료일인 27 일과 11 일까지 난황계수가 0.28 과 0.17 로 나타났다. 이처럼 저장 온도가 높아질수록 저장기간이 경과될수록 난황계수가 낮 아지는 것을 확인 할 수 있었다. 이러한 결과는 신선도가 저하되면 난황내의 수분이 난백으로 이전되어 난황막의 두께가 얇아지고 약해져서 난황의 높이는 낮아지고 폭은 넓어지게 되기 때문인 것으로 보여진다(13).

품질저하 과정 중 난백은 난각의 구멍을 통하여 외부로 수분을 잃는 동시에 난황으로 수분이 혼입되며 이러한 결과 로 부착란(stuck yolk)이나 부패란(mixed yolk)과 같은 불가 식란이 된다(14). 일반적으로 신선란의 난백계수는 0.06 을 

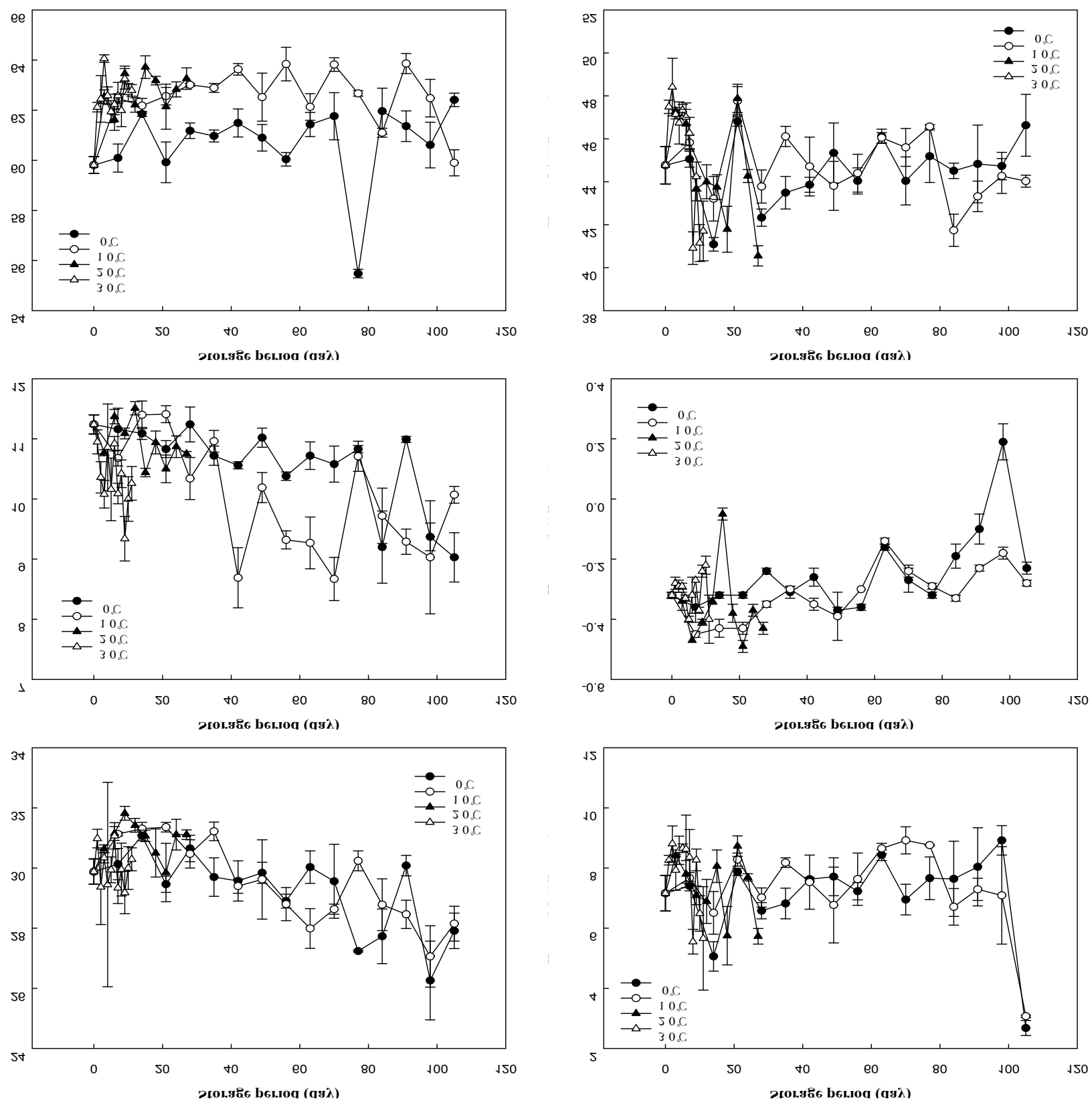

Fig. 4. Changes in the color of egg during storage at $0,10,20$, and $30^{\circ} \mathrm{C}$.

Values are expressed as presented as means $\pm \mathrm{SD}(\mathrm{n}=3)$.

나타내는데, $0^{\circ} \mathrm{C}$ 의 경우 저장 105 일까지 난백계수가 0.08 을 나타내어 저장기간 동안 신선한 상태임을 나타내었다(Fig. 6). 반면에 10,20 및 $30^{\circ} \mathrm{C}$ 에서는 각각 저장 63 일, 9 일 및 3 일 이후에는 난백계수가 0.06 이하로 감소되기 시작하였 다. 난백계수는 온도가 높을수록 저장기간이 경과될수록 급격히 낮아지는 경향을 보였다. 이와 같은 결과는 Suk 등(13)이 저장기간이 경과함에 따라 저장온도가 높을수록 농후난백 높이의 감소폭이 더 컸다고 보고한 결과와 유사한 경향을 나타내었다.

저장온도에 따른 계란의 품질을 결정하는 요인 중 신선
도를 판단할 수 있는 $\mathrm{HU}$ 를 측정하여 나타낸 결과는 Fig. 7 과 같다. $0^{\circ} \mathrm{C}$ 에서 저장하는 동안 신선란의 $\mathrm{HU}$ 의 기준(농 림수산식품부 고시 제 2011-46호 축산물 등급 판정 세부 기준 제 24 조 계란의 품질등급 판정기준인 할란판정 기준 별표 22)인 72 이상으로 나타났다. 반면에 10,20 및 $30^{\circ} \mathrm{C}$ 에 서는 저장기간과 온도에 따라 $\mathrm{HU}$ 가 감소하는 경향을 보였 다. 특히 저장온도가 높을수록 수분의 이동이 커져 난백의 수분이 난황막을 통과하여 난황으로 이동하게 되는데 이때 난황막이 쉽게 깨어지고 또한 계란 신선도의 기준이 되는 $\mathrm{HU}$ 값이 급격히 떨어지며 품질의 변화가 급격하게 일어나 


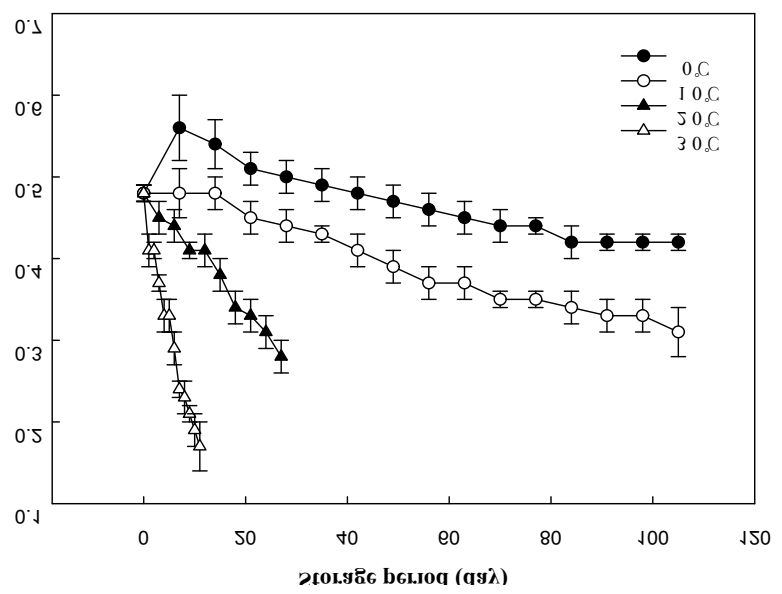

Fig. 5. Changes in the yolk index of egg during storage at 0,10 , 20 , and $30^{\circ} \mathrm{C}$.

Values are presented as means \pm SD $(n=10)$.

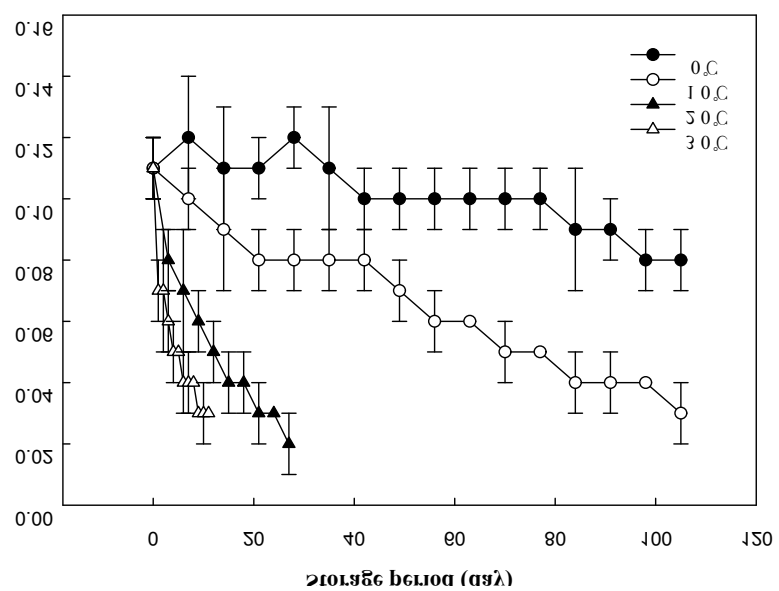

Fig. 6. Changes in the albumen index of egg during storage at 0 , 10,20 , and $30^{\circ} \mathrm{C}$.

Values are presented as means $\pm \mathrm{SD}(\mathrm{n}=10)$.

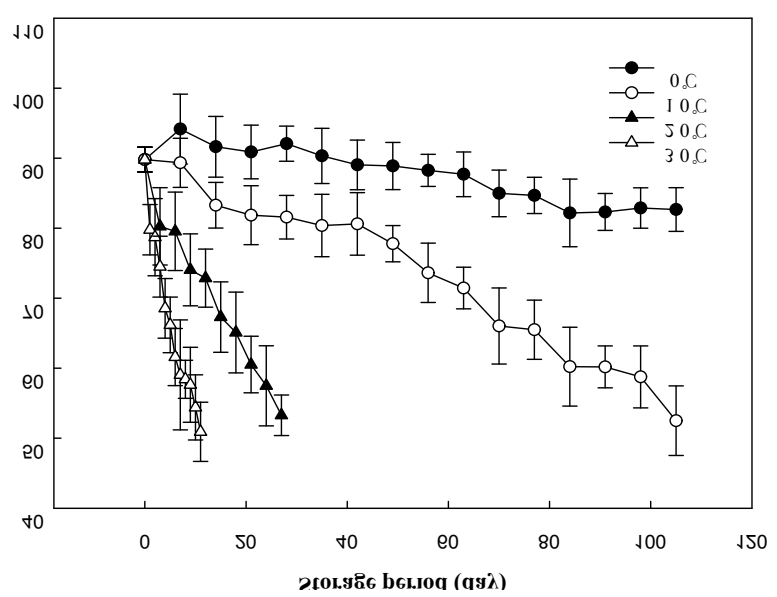

Fig. 7. Changes in the Haugh unit of egg during storage at 0,10 , 20 , and $30^{\circ} \mathrm{C}$.

Values are presented as means $\pm \mathrm{SD}(\mathrm{n}=10)$.
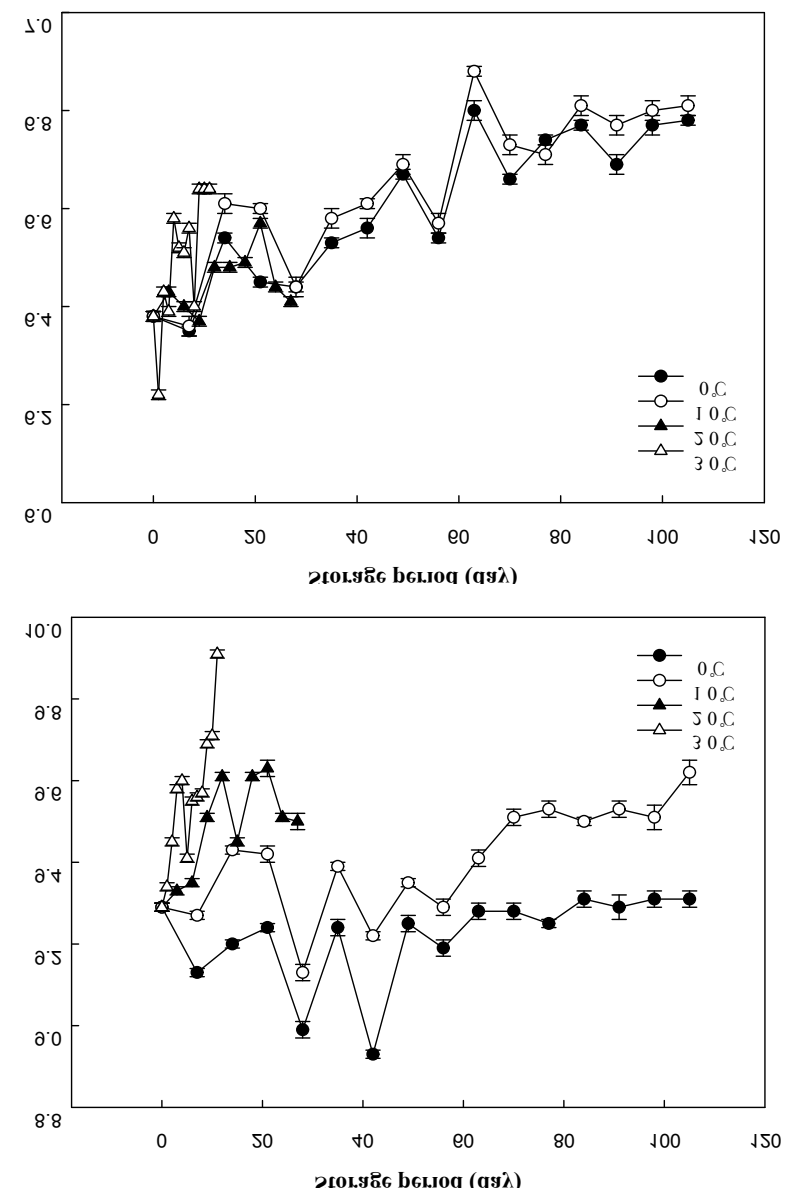

Fig. 8. Changes in the $\mathrm{pH}$ of egg during storage at $0,10,20$, and $30^{\circ} \mathrm{C}$

Values are presented as means $\pm \mathrm{SD}(\mathrm{n}=3)$.

는 것으로 판단된다(15).

일반적으로 신선한 계란의 $\mathrm{pH}$ 는 난백 7.6 7.9 난황 6.0 이나, 저장 중에 난백 9.7 난황 6.8 정도로 증가한다고 알려 져 있다(11). 본 실험에서 난황의 저장 초기 $\mathrm{pH}$ 는 6.38로 나타나 신선한 계란의 난황 $\mathrm{pH}$ 값과 비슷하게 나타났다(Fig. 8). 반면에 난백의 $\mathrm{pH}$ 는 9.29 로 나타나 신선한 난백의 $\mathrm{pH}$ 값 보다 높게 나타났다. 이는 계란의 유통 특성상 산란 직후 유통이 이루어지는 것이 아니라 검란, 세척 및 포장 등의 여러 단계를 거치기 때문인 것으로 사료된다. 저장온도 0 , 10,20 및 $30^{\circ} \mathrm{C}$ 에서 저장하는 동안 난백과 난황의 $\mathrm{pH}$ 가 증가와 감소를 반복하는 경향을 보였으나, 대체적으로 증 가하는 경향을 나타내었다. 이처럼 $\mathrm{pH}$ 가 상승하는 이유는 산란 후 시간이 경과됨에 따라 난각 표면의 기공을 통하여 $\mathrm{CO}_{2}$ 가스가 소실되기 때문인 것으로 여겨진다(16).

계란의 저장온도에 따른 관능적 특성을 9점 척도법으로 조사하였다. 색, 퍼짐성, 이취, 신선도 등의 전반적인 품질 요소들을 종합하여 전반적인 기호도를 조사한 결과 $0^{\circ} \mathrm{C}$ 에 서는 저장기간 105 일 동안 유의적으로 $(\mathrm{p}<0.05)$ 관능적인 품질 변화가 없는 것으로 나타났다(Table 1). 반면에 저장온 
Table 1 . Sensory evaluation of egg during storage at $0^{\circ} \mathrm{C}$

\begin{tabular}{|c|c|c|c|c|c|c|c|c|c|c|c|c|c|c|c|c|}
\hline \multirow{2}{*}{$\begin{array}{c}\text { Sensory } \\
\text { evaluation }\end{array}$} & \multicolumn{16}{|c|}{ Storage period (day) } \\
\hline & 0 & 7 & 14 & 21 & 28 & 35 & 42 & 49 & 56 & 63 & 70 & 77 & 84 & 91 & 98 & 105 \\
\hline Yolk color & $9.00 \pm 0.00^{\mathrm{a}}$ & $8.07 \pm 0.88^{\mathrm{bc}}$ & $7.80 \pm 1.21^{\text {bed }}$ & $8.33 \pm 0.72^{b}$ & $8.33 \pm 0.49^{b}$ & $8.33 \pm 0.90^{b}$ & $7.87 \pm 0.83^{\text {bed }}$ & $7.33 \pm 0.98^{\text {de }}$ & $7.40 \pm 0.99^{\text {de }}$ & $7.67 \pm 0.72^{\text {cd }}$ & $7.60 \pm 1.06^{\mathrm{cd}}$ & $7.60 \pm 1.18^{\mathrm{cd}}$ & $7.60 \pm 1.06^{\mathrm{d}}$ & $7.47 \pm 0.52^{\text {cd }}$ & $7.40 \pm 0.77^{\text {de }}$ & $6.87 \pm 1.06^{\circ}$ \\
\hline $\begin{array}{l}\text { Albumen } \\
\text { color }\end{array}$ & $9.00 \pm 0.00^{2}$ & $8.27 \pm 0.70^{\text {bad }}$ & $8.33 \pm 0.72^{b c}$ & $8.53 \pm 0.64^{\mathrm{ab}}$ & $8.27 \pm 0.46^{\text {bed }}$ & $8.73 \pm 0.46^{a b}$ & $8.33 \pm 0.82^{b c}$ & $7.80 \pm 0.68^{\mathrm{dff}}$ & $7.60 \pm 0.74^{\text {ef }}$ & $8.00 \pm 0.76^{\text {cd }}$ & $8.47 \pm 0.52^{\mathrm{bc}}$ & $7.67 \pm 0.82^{\text {ef }}$ & $7.73 \pm 0.80^{\text {ef }}$ & $7.47 \pm 0.83^{f}$ & $7.73 \pm 0.80^{\text {ef }}$ & $7.53 \pm 0.64^{\text {ef }}$ \\
\hline $\begin{array}{c}\text { Yolk } \\
\text { spreadability }\end{array}$ & $9.00 \pm 0.00^{2}$ & $8.40 \pm 0.63^{\mathrm{bc}}$ & $8.00 \pm 1.56^{\mathrm{de}}$ & $8.80 \pm 0.41^{2 b}$ & $8.33 \pm 0.62^{\mathrm{bc}}$ & $8.47 \pm 0.64^{\text {abc }}$ & $8.13 \pm 0.83^{\text {cd }}$ & $7.47 \pm 0.92^{\text {efg }}$ & $7.27 \pm 1.3^{\text {fg }}$ & $8.27 \pm 0.59^{\mathrm{bc}}$ & $7.87 \pm 1.30^{\text {clef }}$ & $7.60 \pm 0.83^{\text {def }}$ & $7.93 \pm 0.70^{\text {de }}$ & $7.87 \pm 0.52^{\text {deff }}$ & $8.00 \pm 0.76^{\text {de }}$ & $7.00 \pm 1.13^{g}$ \\
\hline $\begin{array}{c}\text { Albumen } \\
\text { spreadability }\end{array}$ & $9.00 \pm 0.00^{\mathrm{a}}$ & $8.47 \pm 0.74^{\text {abc }}$ & $=8.07 \pm 0.88^{\text {bed }}$ & $8.80 \pm 0.41^{\mathrm{a}}$ & $8.47 \pm 0.52^{2 \mathrm{ac}}$ & $8.80 \pm 0.41^{\mathrm{a}}$ & $7.87 \pm 0.74^{d}$ & $7.60 \pm 0.91^{\text {de }}$ & $7.67 \pm 0.82^{\text {de }}$ & $8.00 \pm 0.76^{\mathrm{dd}}$ & $8.53 \pm 0.55^{\mathrm{ab}}$ & $7.27 \pm 1.10^{e}$ & $7.73 \pm 0.80^{\text {de }}$ & $7.60 \pm 0.74^{\text {de }}$ & $7.67 \pm 0.82^{\mathrm{de}}$ & $7.67 \pm 0.82^{\mathrm{de}}$ \\
\hline Offf-flavor & $9.00 \pm 0.00^{2}$ & $8.53 \pm 0.64^{\text {alod }}$ & $8.73 \pm 0.46^{\mathrm{ab}}$ & $8.87 \pm 0.35^{\mathrm{ab}}$ & $8.47 \pm 0.64^{\text {bed }}$ & $8.67 \pm 0.62^{\text {alc }}$ & $8.47 \pm 0.52^{\text {bed }}$ & $8.67 \pm 0.49^{\text {acc }}$ & $8.40 \pm 0.63^{\text {bd }}$ & $8.53 \pm 0.64^{\text {abded }}$ & $8.80 \pm 0.41^{\mathrm{ab}}$ & $8.40 \pm 0.74^{\text {bed }}$ & $8.13 \pm 1.19^{\text {de }}$ & $8.47 \pm 0.74^{\text {bed }}$ & $7.93 \pm 0.96^{\circ}$ & $8.20 \pm 0.56^{\text {ade }}$ \\
\hline Freshness & $9.00 \pm 0.00^{\mathrm{a}}$ & $8.20 \pm 0.77^{\mathrm{d}}$ & $8.00 \pm 0.93^{\mathrm{df}}$ & $8.87 \pm 0.35^{\text {ab }}$ & $8.20 \pm 0.41^{\text {cd }}$ & $8.53 \pm 0.52^{b c}$ & $8.07 \pm 0.70^{\text {de }}$ & $7.60 \pm 0.88^{\text {efgh }}$ & $7.67 \pm 0.72^{\text {dgh }}$ & $7.93 \pm 0.80^{\text {defg }}$ & $8.27 \pm 0.70^{\text {cd }}$ & $7.20 \pm 0.86^{h}$ & $7.67 \pm 0.72^{\text {figh }}$ & $7.47 \pm 0.52^{\text {gh h }^{\text {h }}}$ & $7.53 \pm 0.52^{\text {foh }}$ & $7.40 \pm 0.51^{\mathrm{h}}$ \\
\hline $\begin{array}{c}\text { Overall } \\
\text { acceptability }\end{array}$ & $9.00 \pm 0.00^{\mathrm{a}}$ & $8.33 \pm 0.62^{\mathrm{bc}}$ & $8.00 \pm 1.00^{\text {ale }}$ & $8.73 \pm 0.46^{\mathrm{ab}}$ & $8.33 \pm 0.49^{b c}$ & $8.60 \pm 0.51^{\mathrm{ab}}$ & $8.07 \pm 0.70^{\text {cd }}$ & $7.60 \pm 0.83^{\text {dff }}$ & $7.60 \pm 0.83^{\text {def }}$ & $7.93 \pm 0.80^{\text {cde }}$ & $8.40 \pm 0.74^{b c}$ & $7.27 \pm 0.88^{f}$ & $7.53 \pm 0.74^{\text {ef }}$ & $7.40 \pm 0.51^{\mathrm{f}}$ & $7.53 \pm 0.52^{\text {ef }}$ & $7.20 \pm 0.77^{f}$ \\
\hline
\end{tabular}

Table 2. Sensory evaluation of egg during storage at $10^{\circ} \mathrm{C}$

\begin{tabular}{|c|c|c|c|c|c|c|c|c|c|c|c|c|c|c|c|c|}
\hline \multirow{2}{*}{$\begin{array}{c}\text { Sensory } \\
\text { evaluation }\end{array}$} & \multicolumn{16}{|c|}{ Storage period (day) } \\
\hline & 0 & 7 & 14 & 21 & 28 & 35 & 42 & 49 & 56 & 63 & 70 & 77 & 84 & 91 & 98 & 105 \\
\hline Yolk color & $9.00 \pm 0.00^{2}$ & $7.67 \pm 0.90^{\mathrm{bc}}$ & $7.60 \pm 1.45^{\mathrm{bc}}$ & $8.00 \pm 0.85^{b}$ & $7.40 \pm 0.99^{\text {bed }}$ & $7.27 \pm 0.80^{\text {bed }}$ & $6.87 \pm 0.64^{\text {cde }}$ & $6.47 \pm 1.55^{\circ}$ & $7.67 \pm 0.72^{b c}$ & $7.33 \pm 0.49^{\text {bed }}$ & $6.80 \pm 1.21^{\text {de }}$ & $6.47 \pm 1.55^{\circ}$ & $6.27 \pm 0.80^{\circ}$ & )$^{e} 7.00 \pm 1.07^{\text {de }}$ & $5.53 \pm 1.73^{\mathrm{f}}$ & $5.53 \pm 1.77^{f}$ \\
\hline $\begin{array}{l}\text { Albumen } \\
\text { color }\end{array}$ & $9.00 \pm 0.00^{\mathrm{a}}$ & $8.00 \pm 0.93^{\text {bc }}$ & $8.07 \pm 0.80^{\mathrm{b}}$ & $8.33 \pm 0.72^{b}$ & $7.47 \pm 0.83^{\mathrm{cd}}$ & $7.13 \pm 0.83^{\text {de }}$ & $6.80 \pm 1.08^{\text {eff }}$ & $6.40 \pm 1.30^{f}$ & $7.80 \pm 0.77^{\mathrm{bc}}$ & $6.80 \pm 0.77^{\mathrm{ff}^{\mathrm{f}}}$ & $6.67 \pm 1.11^{\text {eff }}$ & $5.40 \pm 1.24^{g}$ & $4.80 \pm 0.94^{\circ}$ & $4^{g} \quad 3.80 \pm 1.42^{\mathrm{h}}$ & $3.73 \pm 1.16^{\mathrm{h}}$ & h) $3.20 \pm 0.94^{h}$ \\
\hline $\begin{array}{c}\text { Yolk } \\
\text { spreadability }\end{array}$ & $9.00 \pm 0.00^{\mathrm{a}}$ & $8.07 \pm 0.70^{b}$ & $7.60 \pm 1.30^{\text {bed }}$ & $7.93 \pm 0.96^{b}$ & $7.73 \pm 1.03^{\mathrm{bc}}$ & $7.67 \pm 0.82^{b x}$ & $6.87 \pm 0.99^{\text {de }}$ & $5.80 \pm 1.37^{f g}$ & $7.40 \pm 1.18^{\text {bed }}$ & $7.00 \pm 0.93^{\text {cd }}$ & $7.13 \pm 0.64^{\text {od }}$ & $6.13 \pm 1.36^{f}$ & $6.20 \pm 1.08^{f}$ & $6.07 \pm 1.53^{f}$ & $5.87 \pm 1.30^{f}$ & $5.13 \pm 1.30^{g}$ \\
\hline $\begin{array}{l}\text { Albumen } \\
\text { spreadability }\end{array}$ & $9.00 \pm 0.00^{\mathrm{a}}$ & $8.00 \pm 0.85^{b}$ & $7.87 \pm 1.13^{b}$ & $8.60 \pm 0.51^{\mathrm{a}}$ & $7.27 \pm 0.88^{\circ}$ & $3^{c} 7.13 \pm 0.64^{\text {cd }}$ & $6.60 \pm 0.99^{\text {de }}$ & $5.87 \pm 0.99^{f}$ & $7.93 \pm 0.80^{b}$ & $6.67 \pm 0.82^{\text {cle }}$ & $6.33 \pm 1.05^{\text {ef }}$ & $4.67 \pm 1.35^{8}$ & $3.47 \pm 1.06^{h}$ & $3.27 \pm 1.22^{\mathrm{h}}$ & $3.00 \pm 1.00^{\mathrm{hi}}$ & i $2.53 \pm 1.06^{\mathrm{i}}$ \\
\hline Off-flavor & $9.00 \pm 0.00^{\mathrm{a}}$ & $8.00 \pm 0.93^{\text {kd }}$ & $8.60 \pm 0.7^{\mathrm{ab}}$ & $8.53 \pm 0.83^{\mathrm{ab}}$ & $8.47 \pm 0.74^{\text {abc }}$ & $8.33 \pm 0.62^{\text {abcd }}$ & $8.27 \pm 0.46^{\text {ald }}$ & $\underset{\mathrm{cd}}{8.33 \pm 0.72^{2 b}}$ & $7.93 \pm 1.79^{\text {bode }}$ & $7.93 \pm 0.88^{\text {bade }}$ & $8.33 \pm 0.62^{\text {abcd }}$ & $7.67 \pm 1.29 \mathrm{c}$ & $6.93 \pm 1.67^{f}$ & $7.13 \pm 1.60^{\text {ef }}$ & $6.07 \pm 1.44^{g}$ & $7.60 \pm 1.18^{\text {edf }}$ \\
\hline Freshness & $9.00 \pm 0.00^{2}$ & $7.87 \pm 0.74^{\text {bc }}$ & $7.87 \pm 1.30^{\mathrm{bc}}$ & $8.33 \pm 0.82^{b}$ & $7.53 \pm 0.74^{\circ}$ & $7.33 \pm 0.72^{c d}$ & $6.93 \pm 0.70^{\text {de }}$ & $6.07 \pm 0.96^{\mathrm{f}}$ & $7.87 \pm 0.77^{b c}$ & $6.53 \pm 0.83^{\text {ef }}$ & $6.73 \pm 0.96^{\circ}$ & $4.87 \pm 0.99^{9}$ & $3.80 \pm 1.15^{\mathrm{h}}$ & $3.73 \pm 0.70^{\mathrm{h}}$ & $3.27 \pm 0.59^{\mathrm{hi}}$ & $2.93 \pm 0.70^{\mathrm{i}}$ \\
\hline $\begin{array}{c}\text { Overall } \\
\text { acceptability }\end{array}$ & $9.00 \pm 0.00^{\mathrm{a}}$ & $8.00 \pm 0.65^{b \mathrm{c}}$ & $7.73 \pm 1.33^{\text {bed }}$ & $8.27 \pm 0.96^{b}$ & $7.53 \pm 0.74^{\text {de }}$ & $7.33 \pm 0.90^{\mathrm{de}}$ & $7.00 \pm 0.76^{\text {ef }}$ & $6.13 \pm 1.06^{6}$ & $7.80 \pm 0.77^{\text {bd }}$ & $6.60 \pm 0.83^{\mathrm{fg}}$ & $6.53 \pm 1.13^{\mathrm{fg}}$ & $4.73 \pm 0.96^{h}$ & $3.73 \pm 0.96^{\mathrm{i}}$ & $3.60 \pm 0.83^{\mathrm{i}}$ & $3.13 \pm 0.64^{i j}$ & $2.67 \pm 0.98^{j}$ \\
\hline
\end{tabular}

Table 3. Sensory evaluation of egg during storage at $20^{\circ} \mathrm{C}$

\begin{tabular}{|c|c|c|c|c|c|c|c|c|c|c|}
\hline \multirow{2}{*}{$\begin{array}{c}\text { Sensory } \\
\text { evaluation }\end{array}$} & \multicolumn{10}{|c|}{ Storage period (day) } \\
\hline & 0 & 3 & 6 & 9 & 12 & 15 & 18 & 21 & 24 & 27 \\
\hline Yolk color & $9.00 \pm 0.00^{\mathrm{a}}$ & $8.07 \pm 0.70^{b}$ & $7.40 \pm 0.83^{\mathrm{bc}}$ & $6.87 \pm 1.06^{c}$ & $7.47 \pm 0.64^{\mathrm{bc}}$ & $7.00 \pm 1.00^{c}$ & $7.27 \pm 1.28^{c}$ & $5.20 \pm 1.74^{\mathrm{d}}$ & $5.53 \pm 1.88^{\mathrm{d}}$ & $4.93 \pm 1.49^{\mathrm{d}}$ \\
\hline Albumen color & $9.00 \pm 0.00^{\mathrm{s}}$ & $8.07 \pm 0.59^{b}$ & $7.53 \pm 0.99^{b c}$ & $7.53 \pm 0.83^{\mathrm{bc}}$ & $7.20 \pm 0.77^{\mathrm{c}}$ & $6.47 \pm 1.36^{d}$ & $6.13 \pm 1.60^{d}$ & $4.47 \pm 1.68^{\mathrm{e}}$ & $3.20 \pm 1.32^{f}$ & $2.87 \pm 1.13^{f}$ \\
\hline $\begin{array}{c}\text { Yolk } \\
\text { spreadability }\end{array}$ & $9.00 \pm 0.00^{\mathrm{a}}$ & $8.27 \pm 0.59^{\mathrm{ab}}$ & $7.47 \pm 1.19^{b}$ & $7.73 \pm 0.88^{b}$ & $7.73 \pm 1.10^{b}$ & $6.33 \pm 1.29^{c}$ & $7.67 \pm 1.40^{b}$ & $5.07 \pm 1.98^{\mathrm{d}}$ & $4.87 \pm 2.00^{\mathrm{d}}$ & $4.53 \pm 1.73^{\mathrm{d}}$ \\
\hline $\begin{array}{c}\text { Albumen } \\
\text { spreadability }\end{array}$ & $9.00 \pm 0.00^{\mathrm{a}}$ & $8.07 \pm 0.59^{b}$ & $7.13 \pm 0.64^{\mathrm{c}}$ & $7.60 \pm 0.74^{\mathrm{bc}}$ & $7.00 \pm 0.76^{\mathrm{c}}$ & $5.73 \pm 1.39^{\mathrm{d}}$ & $5.40 \pm 1.50^{\mathrm{d}}$ & $2.87 \pm 1.41^{\mathrm{e}}$ & $2.33 \pm 1.18^{\mathrm{ef}}$ & $2.07 \pm 1.22^{\mathrm{f}}$ \\
\hline Off-flavor & $9.00 \pm 0.00^{\mathrm{a}}$ & $7.67 \pm 0.90^{b}$ & $8.40 \pm 0.63^{\mathrm{ab}}$ & $8.27 \pm 0.59^{\mathrm{ab}}$ & $8.27 \pm 1.22^{\mathrm{ab}}$ & $7.73 \pm 1.03^{b}$ & $7.60 \pm 1.50^{b}$ & $6.40 \pm 1.80^{\mathrm{c}}$ & $6.40 \pm 1.55^{\mathrm{c}}$ & $6.60 \pm 1.92^{\mathrm{c}}$ \\
\hline Freshness & $9.00 \pm 0.00^{\mathrm{a}}$ & $8.00 \pm 0.53^{\mathrm{b}}$ & $7.20 \pm 0.68^{c}$ & $7.47 \pm 0.83^{\mathrm{bc}}$ & $7.07 \pm 0.80^{c}$ & $6.20 \pm 0.94^{\mathrm{d}}$ & $6.00 \pm 1.07^{\mathrm{d}}$ & $3.67 \pm 1.40^{\mathrm{e}}$ & $2.93 \pm 1.33^{\mathrm{f}}$ & $2.87 \pm 1.06^{\mathrm{f}}$ \\
\hline $\begin{array}{c}\text { Overall } \\
\text { acceptability }\end{array}$ & $9.00 \pm 0.00^{\mathrm{a}}$ & $8.00 \pm 0.53^{b}$ & $7.13 \pm 0.64^{\mathrm{c}}$ & $7.53 \pm 0.83^{\mathrm{bc}}$ & $7.00 \pm 0.85^{\mathrm{c}}$ & $6.13 \pm 0.99^{\mathrm{d}}$ & $5.93 \pm 1.10^{\mathrm{d}}$ & $3.53 \pm 1.41^{\mathrm{e}}$ & $2.80 \pm 1.37^{\mathrm{f}}$ & $2.80 \pm 1.01^{\mathrm{f}}$ \\
\hline
\end{tabular}

Values are mean $\pm \mathrm{SD}(\mathrm{n}=15)$. 9=excellent, 7=good, 5=moderate/marketable, 3=poor, 1=very poor. Means with the same letter in each row are not significantly different by Duncan's multiple range test $(\mathrm{p}<0.05)$. 
Table 4. Sensory evaluation of egg during storage at $30^{\circ} \mathrm{C}$

\begin{tabular}{|c|c|c|c|c|c|c|c|c|c|c|c|c|}
\hline \multirow{2}{*}{$\begin{array}{c}\text { Sensory } \\
\text { evaluation }\end{array}$} & \multicolumn{12}{|c|}{ Storage period (day) } \\
\hline & 0 & 1 & 2 & 3 & 4 & 5 & 6 & 7 & 8 & 9 & 10 & 11 \\
\hline Yolk color & $9.00 \pm 0.00^{\mathrm{a}}$ & $8.40 \pm 0.74^{\mathrm{a}}$ & $7.67 \pm 0.82^{b}$ & $6.73 \pm 1.10^{c}$ & $5.67 \pm 0.98^{\mathrm{de}}$ & $5.93 \pm 1.28^{\mathrm{d}}$ & $5.73 \pm 1.03^{\mathrm{de}}$ & $5.13 \pm 1.30^{\mathrm{e}}$ & $5.00 \pm 1.56^{\mathrm{e}}$ & $3.40 \pm 1.30^{\mathrm{f}}$ & $4.13 \pm 1.81^{\mathrm{f}}$ & $3.47 \pm 1.73^{\mathrm{f}}$ \\
\hline Albumen color & $9.00 \pm 0.00^{\mathrm{a}}$ & $8.27 \pm 0.80^{b}$ & $7.33 \pm 1.05^{c}$ & $7.20 \pm 0.68^{c}$ & $5.80 \pm 1.32^{\mathrm{d}}$ & $5.67 \pm 1.23^{\mathrm{d}}$ & $4.60 \pm 1.68^{\mathrm{e}}$ & $6.00 \pm 1.46^{d}$ & $3.60 \pm 0.99^{f}$ & $2.47 \pm 0.74^{g}$ & $2.20 \pm 1.08^{\mathrm{g}}$ & $2.53 \pm 1.41^{\mathrm{g}}$ \\
\hline $\begin{array}{c}\text { Yolk } \\
\text { spreadability }\end{array}$ & $9.00 \pm 0.00^{\mathrm{a}}$ & $8.20 \pm 0.77^{\mathrm{b}}$ & $7.33 \pm 1.23^{\mathrm{c}}$ & $6.40 \pm 1.40^{\mathrm{d}}$ & $5.13 \pm 1.25^{\mathrm{e}}$ & $4.80 \pm 1.08^{\mathrm{e}}$ & $5.27 \pm 0.96^{\mathrm{e}}$ & $3.40 \pm 0.83^{\mathrm{f}}$ & $3.60 \pm 1.06^{\mathrm{f}}$ & $2.53 \pm 0.83^{g}$ & $2.60 \pm 0.91^{g}$ & $1.93 \pm 0.59^{\mathrm{h}}$ \\
\hline $\begin{array}{c}\text { Albumen } \\
\text { spreadability }\end{array}$ & $9.00 \pm 0.00^{\mathrm{a}}$ & $8.20 \pm 0.77^{\mathrm{b}}$ & $7.20 \pm 0.86^{\mathrm{C}}$ & $6.73 \pm 0.96^{\mathrm{c}}$ & $5.20 \pm 1.15^{\mathrm{d}}$ & $4.93 \pm 1.16^{d}$ & $3.80 \pm 1.21^{\mathrm{e}}$ & $5.07 \pm 1.33^{\mathrm{d}}$ & $2.73 \pm 0.88^{f}$ & $2.00 \pm 0.53^{g}$ & $1.33 \pm 0.49^{\mathrm{h}}$ & $1.27 \pm 0.46^{\mathrm{h}}$ \\
\hline Off-flavor & $9.00 \pm 0.00^{\mathrm{a}}$ & $8.73 \pm 0.46^{\mathrm{ab}}$ & $8.00 \pm 0.85^{\mathrm{bc}}$ & $7.40 \pm 1.45^{\text {cde }}$ & $7.20 \pm 1.26^{\text {cdef }}$ & $7.60 \pm 1.50^{\text {cd }}$ & $6.93 \pm 1.62^{\operatorname{defg}}$ & $6.67 \pm 1.84^{\mathrm{efg}}$ & $6.40 \pm 1.35^{\mathrm{fg}}$ & $6.07 \pm 1.98^{\mathrm{fg}}$ & $5.40 \pm 1.30^{\mathrm{h}}$ & $6.33 \pm 1.29^{\mathrm{fg}}$ \\
\hline Freshness & $9.00 \pm 0.00^{\mathrm{a}}$ & $8.27 \pm 0.59^{b}$ & $7.27 \pm 0.80^{\mathrm{c}}$ & $6.13 \pm 1.06^{d}$ & $5.00 \pm 0.76^{\mathrm{e}}$ & $4.80 \pm 0.77^{\mathrm{e}}$ & $4.07 \pm 1.16^{\mathrm{f}}$ & $4.20 \pm 0.94^{f}$ & $3.40 \pm 0.51^{g}$ & $2.40 \pm 0.63^{\mathrm{h}}$ & $1.67 \pm 0.49^{\mathrm{i}}$ & $1.53 \pm 0.52^{\mathrm{i}}$ \\
\hline $\begin{array}{c}\text { Overall } \\
\text { acceptability }\end{array}$ & $9.00 \pm 0.00^{\mathrm{a}}$ & $8.27 \pm 0.59^{b}$ & $7.13 \pm 0.83^{\mathrm{c}}$ & $6.13 \pm 1.06^{\mathrm{d}}$ & $5.00 \pm 0.85^{\mathrm{e}}$ & $4.73 \pm 0.80^{e}$ & $3.93 \pm 1.10^{\mathrm{f}}$ & $3.93 \pm 1.10^{\mathrm{f}}$ & $3.13 \pm 0.74^{\mathrm{g}}$ & $2.13 \pm 0.52^{\mathrm{h}}$ & $1.60 \pm 0.51^{\mathrm{i}}$ & $1.47 \pm 0.52^{\mathrm{i}}$ \\
\hline
\end{tabular}

Values are mean $\pm \mathrm{SD}(\mathrm{n}=15)$. 9=excellent, 7=good, 5=moderate/marketable, 3=poor, 1=very poor. Means with the same letter in each row are not significantly different by Duncan's multiple range test $(\mathrm{p}<0.05)$.

도 10(Table 2), 20(Table 3) 및 30(Table 4) ${ }^{\circ} \mathrm{C}$ 의 경우 저장 초기에 전반적인 기호도가 유의적으로 가장 높게 나타났고 $(\mathrm{p}<0.05)$ 저장기간 동안 지속적으로 관능적인 품질변화가 일어났다. 이러한 신선식품의 품질 유지에는 온도와 시간 의 요인이 가장 중요시되므로 보관온도에 따른 품질유지기 간이 달라질 수 있다. 따라서 계란의 보관을 위해 여러 저장 온도에 저장하는 방법을 통하여 일정 수준의 품질을 유지할 수 있는 기간이 어느 정도 될 것인가를 사전에 예측이 가능 하였다.

\section{상관관계 및 품질지표 선정}

계란의 유통 중 품질을 예측할 수 있는 적정 품질지표를 선정하기 위하여 관능적 기호도와 각 품질특성들과의 상관 관계를 분석한 결과는 Table 5 와 같다. 저장 온도별 중량감 모율과 기호도와의 상관관계는 $0,10,20$ 및 $30^{\circ} \mathrm{C}$ 에서 각각 $\mathrm{r}=-0.78, \mathrm{r}=-0.93, \mathrm{r}=-0.95$ 및 $\mathrm{r}=-0.99$ 로 모든 온도 조건에서 유의적인 상관관계를 보였으며 $(\mathrm{p}<0.01)$, 온도가 높을수록 높은 상관계수를 나타내었다. 그러므로 중량감모율 측정 변화는 관능적 기호도와 높은 상관관계를 나타냄에 따라 신선도를 판정하는 품질지표로 선정하여 적용 하는 것이 적절한 것으로 판단된다.

비중과 기호도와의 상관관계는 $0,10,20$ 및 $30^{\circ} \mathrm{C}$ 에서 각각 $\mathrm{r}=0.75, \mathrm{r}=0.79, \mathrm{r}=0.71$ 및 $\mathrm{r}=0.88$ 로 모든 온도 조건에 서 유의적인 상관관계를 보였다( $\mathrm{p}<0.05)$. 따라서 다른 품질 인자와 비교하여 적정 지표로의 선정에 가능성을 보여주었 다.

난황의 색도와 관능적 기호도와의 상관관계를 분석한 결과 녹색에서 붉은색 정도를 나타내는 $\mathrm{a}$ 값은 $30^{\circ} \mathrm{C}$ 에서만 유의적인 상관관계를 보였고, 황색도를 나타내는 $\mathrm{b}$ 값은 $0^{\circ} \mathrm{C}$ 와 $10^{\circ} \mathrm{C}$ 에서만 상관관계에 대한 유의성이 인정되었다. 난백의 색도와 관능적 기호도와의 상관관계에서 밝기를 나타내는 $\mathrm{L}$ 값은 $30^{\circ} \mathrm{C}$ a값은 $10^{\circ} \mathrm{C}$ 에서만 유의성이 나타났
다. 그러므로 계란의 난황과 난백의 색도는 시간이 경과되 어도 상이한 결과를 보이지 않아 품질평가 지표로 이용하기 에는 적절하지 않은 것으로 생각된다.

난황계수와 기호도와의 상관관계는 $0,10,20$ 및 $30^{\circ} \mathrm{C}$ 에 서 각각 $\mathrm{r}=0.58, \mathrm{r}=0.87, \mathrm{r}=0.96$ 및 $\mathrm{r}=0.98$ 로 모든 온도 조건에서 유의적인 상관관계를 보였다 $(\mathrm{p}<0.05) .0^{\circ} \mathrm{C}$ 가 10 , 20 및 $30^{\circ} \mathrm{C}$ 에 비하여 낮은 상관관계를 나타내었는데, 이는 저장기간 동안 품질변화가 크게 나타나지 않았기 때문으로 여겨진다.

난백계수와 기호도와의 상관관계는 $0,10,20$ 및 $30^{\circ} \mathrm{C}$ 에 서 각각 $\mathrm{r}=0.66, \mathrm{r}=0.89, \mathrm{r}=0.89$ 및 $\mathrm{r}=0.93$ 으로 모든 온도 조건에서 유의적인 상관관계를 보였으며 $(\mathrm{p}<0.01)$, 고온이 저온보다 높은 상관관계를 나타내었다. 난백의 퍼짐성은 저장기간과 온도에 따라서 육안으로 변화하는 모습을 관찰 할 수 있을 정도이기 때문에 이처럼 높은 상관관계를 나타 낸 것으로 여겨진다. 따라서 난백계수 측정 변화는 신선도 를 판정하는 품질지표로 선정하여 적용 하는 것이 적절한 것으로 사료된다.

$\mathrm{HU}$ 와 기호도와의 상관관계는 $0,10,20$ 및 $30^{\circ} \mathrm{C}$ 에서 각각 $\mathrm{r}=0.64, \mathrm{r}=0.92, \mathrm{r}=0.96$ 및 $\mathrm{r}=0.98$ 로 모든 온도 조건에서 유의적인 상관관계를 보였으며 $(\mathrm{p}<0.01)$, 온도가 높을수록 높은 상관계수를 나타내었다. 이러한 결과는 $\mathrm{HU}$ 의 측정값 이 시간의 경과와 직선적인 상관관계를 가지고 있기 때문인 것으로 보여진다. $\mathrm{HU}$ 측정 변화는 관능적 기호도와 높은 상관관계를 나타냄에 따라 신선도를 판정하는 품질지표로 선정하여 적용 하는 것이 적절한 것으로 판단된다.

난황의 $\mathrm{pH}$ 와 관능적 기호도와의 상관관계를 분석한 결 과 0,10 및 $30^{\circ} \mathrm{C}$ 에서는 유의적인 상관관계를 보였으나, $20^{\circ} \mathrm{C}$ 에서는 상관관계에 대한 유의성은 인정되지 않았다. 또한 난백의 $\mathrm{pH}$ 와 관능적 기호도와의 상관관계에서 역시 $10^{\circ} \mathrm{C}$ 와 $30^{\circ} \mathrm{C}$ 에서만 유의성이 인정되었다. 이처럼 계란의 $\mathrm{pH}$ 는 시간의 경과에 따라서 일정한 변화를 보이지 않았고 
Table 5. Pearson's correlation coefficients between sensory preference and quality characteristics of egg

\begin{tabular}{|c|c|c|c|c|}
\hline \multicolumn{2}{|c|}{ Quality characteristics } & $\begin{array}{c}\text { Storage } \\
\text { temperature }\left({ }^{\circ} \mathrm{C}\right)\end{array}$ & $\begin{array}{l}\text { Correlation } \\
\text { coefficient (r) }\end{array}$ & $\begin{array}{c}\text { Statistical } \\
\text { significance }\end{array}$ \\
\hline \multirow{4}{*}{\multicolumn{2}{|c|}{ Weight-loss }} & 0 & -0.78 & ** \\
\hline & & 10 & -0.93 & $\star *$ \\
\hline & & 20 & -0.95 & $* *$ \\
\hline & & 30 & -0.99 & $\star *$ \\
\hline \multirow{4}{*}{\multicolumn{2}{|c|}{ Specific gravity }} & 0 & 0.75 & $\star *$ \\
\hline & & 10 & 0.79 & $* *$ \\
\hline & & 20 & 0.71 & * \\
\hline & & 30 & 0.88 & ** \\
\hline \multirow{12}{*}{$\begin{array}{l}\text { Yolk } \\
\text { color }\end{array}$} & \multirow{4}{*}{$\mathrm{L}$} & 0 & 0.11 & NS \\
\hline & & 10 & 0.14 & NS \\
\hline & & 20 & -0.46 & NS \\
\hline & & 30 & -0.49 & NS \\
\hline & \multirow{4}{*}{$\mathrm{a}$} & 0 & 0.46 & NS \\
\hline & & 10 & 0.45 & NS \\
\hline & & 20 & 0.52 & NS \\
\hline & & 30 & 0.63 & * \\
\hline & \multirow{4}{*}{$\mathrm{b}$} & 0 & 0.52 & * \\
\hline & & 10 & 0.68 & $\star *$ \\
\hline & & 20 & -0.01 & NS \\
\hline & & 30 & 0.14 & NS \\
\hline \multirow{12}{*}{$\begin{array}{l}\text { Albumen } \\
\text { color }\end{array}$} & \multirow{4}{*}{$\mathrm{L}$} & 0 & -0.10 & NS \\
\hline & & 10 & 0.42 & NS \\
\hline & & 20 & 0.27 & NS \\
\hline & & 30 & 0.65 & * \\
\hline & \multirow{4}{*}{$\mathrm{a}$} & 0 & -0.34 & NS \\
\hline & & 10 & -0.51 & * \\
\hline & & 20 & 0.25 & NS \\
\hline & & 30 & 0.03 & NS \\
\hline & \multirow{4}{*}{$\mathrm{b}$} & 0 & -0.07 & NS \\
\hline & & 10 & 0.44 & NS \\
\hline & & 20 & 0.11 & NS \\
\hline & & 30 & 0.43 & NS \\
\hline \multirow{4}{*}{\multicolumn{2}{|c|}{ Yolk index }} & 0 & 0.58 & * \\
\hline & & 10 & 0.87 & ** \\
\hline & & 20 & 0.96 & $* *$ \\
\hline & & 30 & 0.98 & ** \\
\hline \multirow{4}{*}{\multicolumn{2}{|c|}{ Albumen index }} & 0 & 0.66 & $\star \star *$ \\
\hline & & 10 & 0.89 & $* *$ \\
\hline & & 20 & 0.89 & $\star \star$ \\
\hline & & 30 & 0.93 & $\star \star$ \\
\hline \multirow{4}{*}{\multicolumn{2}{|c|}{ Haugh unit }} & 0 & 0.64 & $\star *$ \\
\hline & & 10 & 0.92 & $* *$ \\
\hline & & 20 & 0.96 & $\star *$ \\
\hline & & 30 & 0.98 & $* *$ \\
\hline \multirow{4}{*}{\multicolumn{2}{|c|}{ Yolk pH }} & 0 & -0.75 & $* *$ \\
\hline & & 10 & -0.77 & $* *$ \\
\hline & & 20 & -0.43 & NS \\
\hline & & 30 & -0.82 & * \\
\hline \multirow{4}{*}{\multicolumn{2}{|c|}{ Albumen $\mathrm{pH}$}} & 0 & -0.19 & NS \\
\hline & & 10 & -0.72 & $* *$ \\
\hline & & 20 & -0.57 & NS \\
\hline & & 30 & -0.88 & $* *$ \\
\hline
\end{tabular}

${ }^{{ }^{p} \mathrm{p}<0.05,{ }^{\star *} \mathrm{p}<0.01}$.
각기 상이한 결과를 나타내어 품질평가 지표로 이용하기에 는 추가 연구가 더 필요한 것으로 생각된다.

\section{요 약}

본 연구는 국내에서 유통되고 있는 계란의 유통 중 신선 도를 예측하기 위하여 적정 품질지표를 선정하고자 수행되 었다. 산란 직후 $0,10,20$ 및 $30^{\circ} \mathrm{C}$ 에서 저장하면서 중량감모 율, 비중, 색도, 난황계수, 난백계수, Haugh unit(HU), $\mathrm{pH}$ 및 관능특성 변화를 조사한 후 각 품질특성과 관능적 기호 도와의 상관관계를 분석하였다. 저장온도에 따른 중량감모 율, 비중, 난황계수, 난백계수 및 $\mathrm{HU}$ 와 기호도와의 상관관 계는 모든 온도 조건에서 유의적인 상관관계를 나타내었다 $(\mathrm{p}<0.05)$. 특히 중량감모율과 기호도와의 상관관계는 0,10 , 20 및 $30^{\circ} \mathrm{C}$ 에서 각각 $\mathrm{r}=-0.78, \mathrm{r}=-0.93, \mathrm{r}=-0.95$ 및 $\mathrm{r}=-0.99$ 로 난백계수와 기호도와의 상관관계는 $\mathrm{r}=0.66, \mathrm{r}=0.89, \mathrm{r}=0.89$ 및 $\mathrm{r}=0.93$ 으로 그리고 $\mathrm{HU}$ 와 기호도와의 상관계수는 $\mathrm{r}$ $=0.64, \mathrm{r}=0.92, \mathrm{r}=0.96$ 및 $\mathrm{r}=0.98$ 로 유의적으로 온도가 높을수록 높은 상관계수를 보였다( $<<0.01)$. 반면에 색도와 $\mathrm{pH}$ 는 각기 상이한 결과를 나타내어 품질평가 자료로 이용 하기에는 추가 연구가 필요한 것으로 여겨진다. 따라서 모 든 저장온도에서 관능적 기호도와 높은 상관관계를 나타낸 중량감모율, 비중, 난황계수, 난백계수 및 $\mathrm{HU}$ 의 변화를 계 란의 유통 중 신선도 예측을 위한 품질지표로 선정하여 적용하는 것이 적절한 것으로 판단되었다.

\section{References}

1. Kim DH, Song HP, Lee YS, Cha BS, Kim BK, Byun MW (2004) Effect of gamma irradiation on the shelf stability of whole baked egg. Korean J Food Preserv, 11, 394-399

2. Koo NS, Wang SG, Park JM (2002) Change of fatty acid content in egg yolk oil of various chicken eggs during storage. Korean J Soc Food Sci Nutr, 31, 184-188

3. Noh JJ, Jeon SY, Park BS, Kim SM, Kim HS, Kim HJ, Jo CH (2013) Investigation of reliability of automatic cracked and bloody egg detector. Korean J Food Preserv, 20, 69-75

4. Lee JC, Kim SH, Sun CW, Kim CH, Jung S, Lee JH, Jo CH (2013) Comparison of principle components and internal quality of eggs by age of laying hens and weight standard. Korean J Poult Sci, 40, 49-55

5. Kang HK, Kang GH, Na JC, Yu DJ, Kim DW, Lee SJ, Kim, SH (2008) Effect of feeding Rhus verniciflua extract 
on egg quality and performance of laying hens. Korean J Food Sci An, 28, 610-615

6. Lee SM, Kim KH, Lee JG, Park EJ, Lee SW, Hong JH (2002) Hygienic quality of eggs in the department food stores in the Incheon metropolitan area. Korean J Food Hyg Safety, 17, 129-136

7. Chun MS, Hong SH (2009) Identification of microorganisms from eggs in hypermarket in the northern Gyeonggi area. Korean J Food Sci Nutr, 22, 396-401

8. Hong SH, Ra DK, Yun GR, Joung YJ, Nam JH, Cheong $\mathrm{EH}$, Lee JG, Lee SM (2012) Investigation for freshness and nutritive components of the eggs sold in Incheon. Korean J Vet Serv, 35, 119-128

9. Park HJ, Min KJ, Park NY, Cho JI, Lee SH, Hwang IG, Heo JJ, Yoon KS (2013) Estimation on the consumption patterns of potentially hazardous foods with high consumer risk perception. Korean J Food Sci Technol, 45, 59-69

10. Kim HS, Kim SM, No JJ, Lee JI, Lee HJ, Jo CH (2012) Effect of age of laying hens and grade of egg shell abnormality on internal egg quality. Korean J Ani Sci Technol, 54, 43-49
11. Lee SM, Hong CH (2005) Changes of egg quality according to eggshell treatment and storage condition. Korean J Vet Serv, 28, 225-234

12. Kim HT, Ko HJ, Kim KY, Kato K, Kita Y, Nishizu $\mathrm{T}$ (2007) Determination of egg freshness and internal quality measurement using image analysis. Korean J Biosystems Eng, 32, 166-172

13. Suk OY, Kwon JT (2004) Effects of egg storage, storage temperature, and insemination of hens egg quality. Korean J Poult Sci, 31, 203-212

14. Jang YI, Yoo JH, Han SW, Jang KS (2001) Quality characteristics of shell eggs stored in artificial cave for energy saving. Korean J Food Eng Prog, 5, 202-211

15. An JH, Park JM, Gu JK, Yoon SJ, Lee JS, Kim JM, Kim SH, Kim RJ, Park JW, Song SO, Wee SH, Kim JM (2012) A study of establishment and exploitation of bio-markets for determination of shelf-life of eggs and egg products. Korean J Food Sci An, 32, 354-363

16. Lee SM, Kim KH, Hong CH (2002) Changes of egg quality during storage. Korean J Vet Serv, 25, 15-22

(접수 2014년 4월 25일 수정 2014년 7월 23일 채택 2014년 8월 7일) 